\title{
Effect of inlet morphology and wave action on pollutant pathways and sediment dynamics in a coastal stream
}

\author{
Anabela Oliveira, ${ }^{1}$ André B. Fortunato, ${ }^{1}$ Martha Guerreiro, ${ }^{1}$ Xavier Bertin, ${ }^{1}$ Nicolas \\ Bruneau, ${ }^{1}$ Marta Rodrigues, ${ }^{1}$ Rui Taborda, ${ }^{2}$ César Andrade, ${ }^{2}$ Ana Maria Silva, ${ }^{2}$ Carlos \\ Antunes, ${ }^{2}$ Paula Freire, ${ }^{1}$ L. Simões Pedro, ${ }^{1}$ Guillaume Dodet,,${ }^{2,1}$ Carlos Loureiro, ${ }^{3}$ Ana \\ Mendes ${ }^{1}$
}

\begin{abstract}
Hydrodynamics and water renewal of intermittent coastal streams are highly variable, at various time scales, due to the very active morphodynamic behavior of their inlets. Due to this strong dynamics, the pathways of water-borne materials - and the consequences of contaminated discharges - can depend strongly on the morphology and environmental conditions. Predicting the fate of contaminants in these systems requires coupled numerical models accounting for the major physical and water quality processes.

We aim at improving the understanding of the impact of inlet morphology and wave action on the pollutant and sediment pathways of these small coastal systems, based on a suite of calibrated and validated coupled models. Two analyses, based on particle simulations, are presented to assess sediment dynamics and pollutant pathways for several conditions. Results show that waves have a major effect on the fate of waterborne materials in the estuary. Wave-induced currents sweep away materials coming out of the estuary, while wave-induced setup has a profound effect on tidal propagation, water levels and velocities in the estuary, promoting the upstream transport of pollutants.

\footnotetext{
${ }^{1}$ National Laboratory for Civil Engineering, Av. do Brasil, 101, 1700-066 Lisbon, Portugal; \{aoliveira, afortunato, mguerreiro, xbertin, nbruneau, mfrodrigues, pfreire, lsimoes, gdodet, amendes\}@1nec.pt.

${ }^{2}$ Faculdade de Ciências da Universidade de Lisboa, Campo Grande, Ed. C6, 1749-016 Lisboa, Portugal; \{rtaborda, candrade, amasilva, cmantunes\}@fc.ul.pt.

${ }^{3}$ CIMA, Universidade do Algarve, Campus de Gambelas, Ed. 7, 8005-139 Faro, Portugal; cloureiro@ualg.pt.
} 


\section{Introduction}

The small estuaries and coastal lagoons associated to coastal streams often have an active morphodynamic behavior, due to the combination of strong tidal and waveinduced currents, shallow channels and their variable and intermittent freshwater inflow. Also, as a result of their shallow bathymetry, even small absolute changes in depth can have relatively strong impacts on hydrodynamics. Hydrodynamics, morphodynamics and water renewal are thus highly variable, at annual, seasonal and shorter time scales, which hampers the monitoring, the forecasting and, ultimately, the management of these systems. This strong dynamics makes the intermittent coastal streams very sensitive to contamination/pollution, as a contaminated discharge may have very different consequences depending on the capacity for water renewal of the system at that particular time.

A second distinguishing characteristic of these small estuaries is the importance of waves relative to tides. On the one hand, tidal prisms are small, leading to weak ebb jets. The relative importance of littoral currents and other wave-induced processes on the motion of the water masses leaving these estuaries is therefore higher than in larger systems. On the other hand, because these systems are shallow, waves can have a significant effect on the total water depth near the tidal inlets. Indeed, the setup of the water surface induced by breaking waves can be of the order of a few tens of centimeters, which can represent a significant fraction of the total water depth of the inlets at low tide.

Properly managing these complex systems requires the ability to predict the fate of contaminants discharged into the system, which can only be achieved through the simultaneous consideration of all relevant physical processes, including wave-current interactions, bathymetric evolution and water quality processes. Coupled numerical models, which can simulate the full variability of environmental conditions and the interaction between processes, are a promising approach (Suzuki et al., 1998, Oliveira et al., 2006, 2007).

In this context, the primary goal of this work is to improve the understanding of the impact of morphological changes of the inlet and the effect of waves on the water quality of a coastal stream, based on a suite of coupled models, calibrated and validated for different environmental conditions. The same set of models is then used to assess the effect of waves on the sediment dynamics inside the estuary, as sediments can act as sources and sinks for contaminants. The Aljezur coastal stream (SW Portugal) is used as a case study, as it presents a very dynamic inlet, which may close occasionally, and has several potential contamination sources that can deteriorate its water quality.

Circulation is evaluated using a 2D morphodynamic modeling system (MORSYS2D, Fortunato and Oliveira, 2004, Bertin et al., 2009a). Currently, this modeling system softly couples the hydrodynamic models ADCIRC (www.adcirc.org) or ELCIRC (www.stccmop.org/CORIE/modeling/elcirc/index.html), the wave model SWAN (www.wldelft.nl/soft/swan), the sand transport and bottom update model SAND2D (Fortunato and Oliveira, 2004) and the water quality model VELA (Oliveira and 
Fortunato, 2002a). The two circulation models differ only in the numerical properties: ELCIRC runs faster in serial mode, while ADCIRC is the most efficient in parallel. Regardless of the circulation model, coupling between wave and currents includes the generation of currents and set-up due to gradients of radiation stresses. The coupling preserves the individuality of the codes, which are launched through a steering C-shell script. The application of the modeling system to the Aljezur system is supported by two field surveys, carried out under maritime summer and winter conditions, and for spring and neap tides (May and September 2008).

The impact of inlet morphology and wave action on water quality is based on the simulation of pollutant pathways and sediment dynamics. The Lagrangian transport model VELApart (Oliveira and Fortunato, 2002b) is used to determine the pathways of pollutants released at different locations and to assess the impact of the inlet variability on the distribution of contamination. The simulations are performed for several release times within the tidal cycle, based on hydrodynamic simulations obtained from the coupled modeling system, and conducted for different inlet morphologies. Model results are then integrated to quantify the dependence of pollutant dynamics on the inlet morphology and to highlight the importance of waves. The same model is then used in quasi-3D mode to identify the sediment pathways and to assess the impact of the inlet morphology and waves on their distribution.

The paper is divided in 5 sections besides this Introduction. Section 2 presents the main characteristics of the study site. Section 3 briefly describes the three models used. The models set-up and validation and the numerical tests are described next. Results are presented in section 5 , and the paper closes with a summary of the major conclusions.

\section{Description of the Aljezur coastal stream}

The Aljezur coastal stream, located on the Southwest coast of Portugal (Figure 1), has a very dynamic inlet, which may close occasionally, and undergoes significant changes. The estuary is about $8 \mathrm{~km}$ long, 5-100 $\mathrm{m}$ wide and very shallow (typical depths within a $2 \mathrm{~m}$ range around mean sea level). There are extensive tidal flats between kilometers 2 and 3, part of which have given place to an aquaculture facility.

Ocean tides are semi-diurnal, with tidal ranges between 1 and $4 \mathrm{~m}$. The wave regime is highly energetic, with $3 \mathrm{~m}$ wave heights being exceeded roughly between 5 and $10 \%$ of the time. Sediments are mostly sandy in the lower estuary (within $1.4 \mathrm{~km}$ of the inlet mouth), while different mixtures of cohesive and non-cohesive sediments are present in the upper estuary.

The estuary has three major potential contamination sources: wastewater facility discharges, responsible for most of the freshwater inflow to the estuary in the summer (kilometer 9), discharges from a large aquaculture facility (kilometer 2.4) and contamination from cattle feces (around kilometer 5), mostly during rain events. This coastal system has a significant ecological and local economical value, as it is located within an environmentally protected area and has extensive recreational use. Hence, maintaining high standards of water quality is a growing concern for the authorities. 


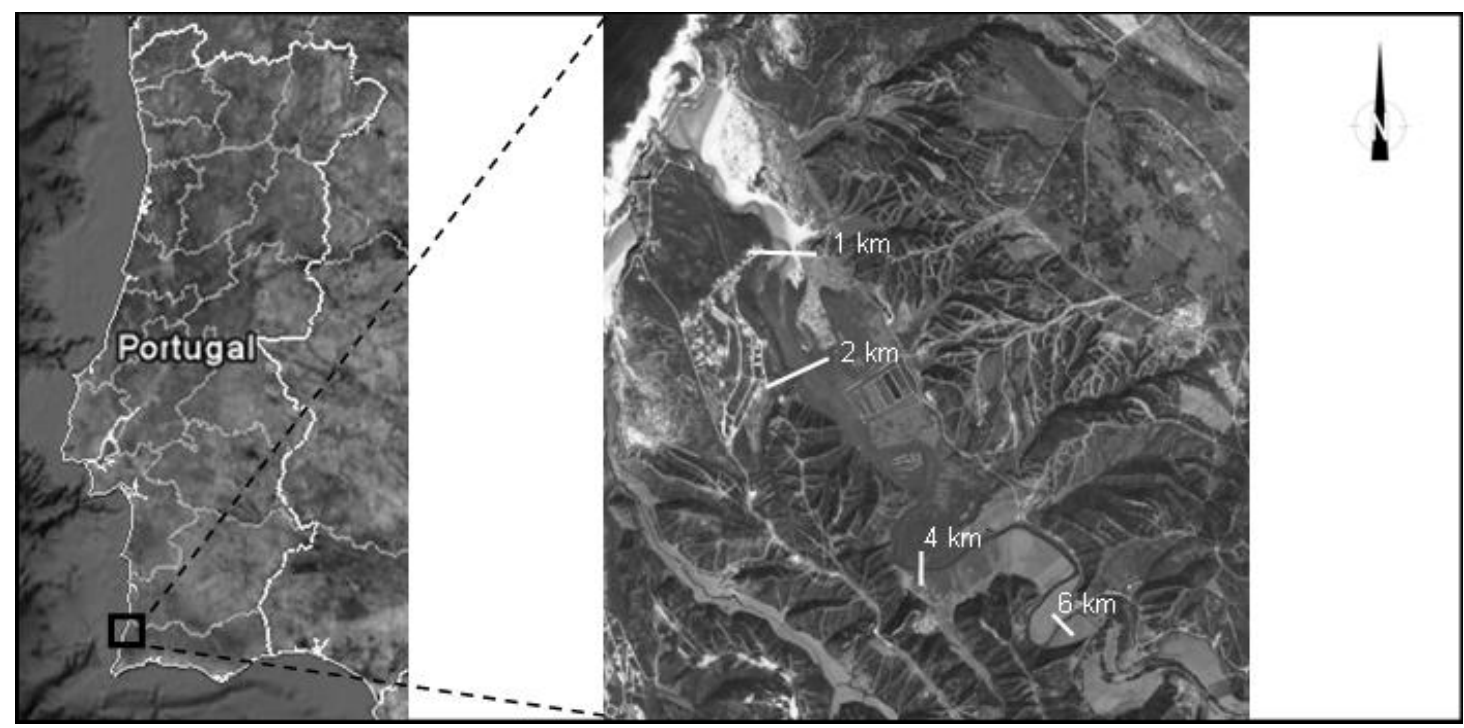

Figure 1. The Aljezur coastal stream: geographical location and aerial photo (source: Google Earth).

\section{Modeling system description}

The analysis is based on the modeling system MORSYS2D (Figure 2). MORSYS2D is a C-shell script that runs independent models, manages the transfer of information between them and performs control checks. The system includes several models for circulation, wave propagation, scalar transport and water quality, sediment transport and bottom evolution. Here, only the modules used in the present application are described. Further details on MORSYS2D and its applications can be found elsewhere (e.g., Fortunato and Oliveira, 2004; Oliveira et al., 2007, 2008; Bertin et al., 2009a-c; Fortunato et al., 2009).

Three models are used herein: the shallow water hydrodynamic model ELCIRC (Zhang et al., 2004), the spectral wave model SWAN (Booij et al., 1999) and the particle tracking model VELApart (Oliveira and Baptista, 1998, Oliveira and Fortunato, 2002b), which is forced by the outputs of ELCIRC. ELCIRC and SWAN are described only briefly, and the reader is referred to the original publications for details. The present version of VELApart is described in more detail, as it has not been published in the open literature previously.

\subsection{The hydrodynamic model ELCIRC}

ELCIRC, an open source community model developed at the Center for Coastal Margin Observation and Prediction, solves the fully non-linear, three-dimensional, baroclinic shallow water equations, coupled to transport equations for salt and heat. Forcings include tides, tidal potential, wind stress, gradients of radiation stresses and solar radiation. Several turbulence closure schemes are implemented. 
The equations are solved with a finite volume technique for volume conservation and a natural treatment of wetting and drying. The horizontal domain is discretized with an unstructured mesh for flexibility, and z-coordinates are used in the vertical. A semiimplicit time-stepping algorithm and the Lagrangian treatment of the advective terms ensure stability at large time steps.

In MORSYS2D, ELCIRC is run in 2D depth-averaged mode (i.e., with a single vertical layer), which avoids, in particular, the difficulty in representing 3D wave radiation stresses.

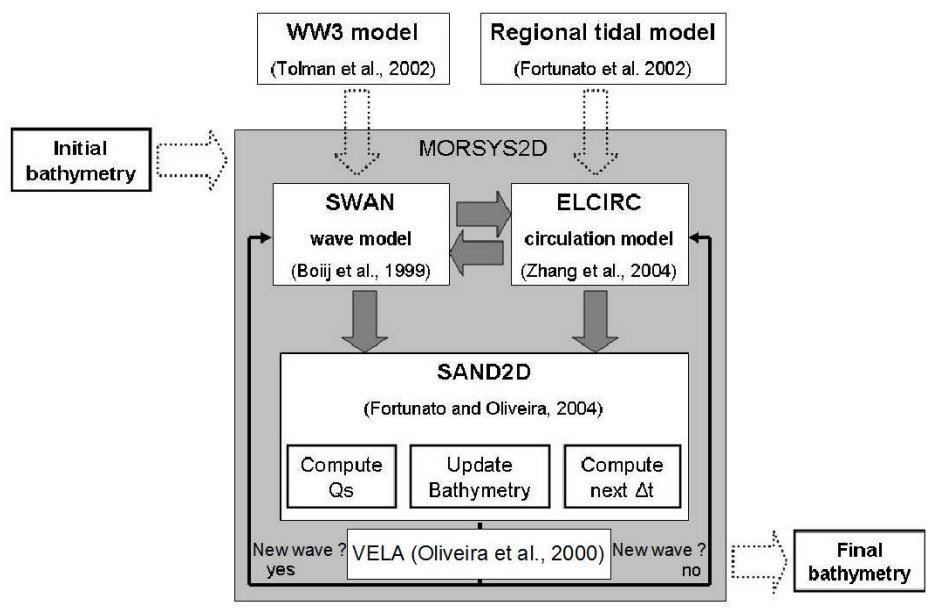

Figure 2. The MORSYS2D modeling system.

\subsection{The wave propagation model SWAN}

The SWAN spectral wave model solves the wave action density balance equation (Booij et al., 1999) and is used in MORSY2D in stationary mode to simulate wave propagation and deformation from the open sea up to the coast. This model was set to take into account the bottom friction (formulation of Madsen et al., 1988), wave breaking (model of Battjes and Janssen, 1978), triad wave-wave interaction and wave propagation within a time-dependent water level. In most applications, other processes such as wind growth, energy dissipation by whitecapping or quadruplet interactions are considered negligible and turned off. Depending on the purpose of the study, SWAN can be forced at its open boundary by constant wave parameters, by time series of wave parameters originating from the WAVEWATCH3 (WW3) model (Tolman et al., 2002) or by time-series of wave spectra originating from the regional wave model of Dodet et al. (2010).

Significant wave height, direction and wavelength produced by SWAN are used to compute gradients of radiation stresses, according to wave linear theory (LonguetHiggins and Stewart, 1964) and following Bain and Cobb (2003), to force the hydrodynamic model. 


\subsection{The particle-tracking model VELApart}

\subsubsection{Physical formulation}

VELApart is a quasi-3D particle tracking model for surface waters. It is driven by a $2 \mathrm{D}$ depth-averaged flow field, and computes the trajectories of individual particles carried by the flow. When used in 2D mode, VELApart uses the depth-averaged velocities provided by ELCIRC to compute the trajectories of passive tracers. To simulate the fate of suspended sediments, VELApart can also be used in quasi-3D mode. In this case, the horizontal tracking assumes a logarithmic velocity profile in the vertical. The vertical motion includes gravitational effects, turbulent diffusion and an approximate representation of vertical advection.

VELApart solves the advection-diffusion equation for individual non-reactive particles of water in sigma coordinates:

$$
\frac{\partial c}{\partial t}+u \frac{\partial c}{\partial x}+v \frac{\partial c}{\partial y}+\theta \frac{\partial c}{\partial \sigma}=\frac{D_{h}}{H} \frac{\partial}{\partial x_{i}}\left(H \frac{\partial c}{\partial x_{i}}\right)+\frac{\partial}{\partial \sigma}\left(\frac{D_{v}}{H^{2}} \frac{\partial c}{\partial \sigma}\right)
$$

where $c$ represents the concentration, $(x, y, z)$ are the cartesian coordinates, $(u, v, w)$ are the velocity components, $D_{h}$ and $D_{v}$ are the horizontal and vertical eddy viscosity coefficients, respectively, and $H$ is depth. The vertical coordinate $\sigma$ is given by:

$$
\sigma=\frac{z-\eta}{H}
$$

where $\eta$ represents the water surface elevation.

When VELApart is used in 2D mode, $\theta$ and $D_{v}$ are set to zero, and the concentration and the velocities are depth-averaged. When VELApart is used in quasi-3D mode, the vertical distribution of velocity is assumed logarithmic:

$$
\vec{u}(\sigma)=U \frac{\ln \left(H(\sigma+1) / z_{0}\right)}{\ln \left(H / z_{0}\right)-1}
$$

where $U$ is the depth-averaged velocity and $z_{0}$ is the roughness height, taken as $1 \mathrm{~cm}$.

The vertical velocity in $\sigma$ coordinates, $\theta$, is given by:

$$
\theta=\frac{1}{H}\left(w+w_{s}-(\sigma+1) \frac{\partial \eta}{\partial t}-u\left(\frac{\partial \eta}{\partial x}+\sigma \frac{\partial H}{\partial x}\right)-v\left(\frac{\partial \eta}{\partial y}+\sigma \frac{\partial H}{\partial y}\right)\right)
$$

where $w_{s}$ is the settling velocity, which can be specified by the user or evaluated with the formula of van Rijn (1984) based on the sediment grain size. Assuming that the horizontal velocity is constant in the vertical, equation (4) reduces to:

$$
\theta=\frac{w_{s}}{H}
$$

This simplification is equivalent to assuming that, for $w_{s}=0$, the particles follow along a $\sigma$-plane, i.e., that their relative position in the water column remains constant.

Finally, the diffusion terms are split in two, in order to facilitate their numerical treatment, by using a random walk method: 


$$
\frac{\partial}{\partial \sigma}\left(\frac{D_{z z}}{H^{2}} \frac{\partial c}{\partial \sigma}\right)=\frac{\partial^{2}}{\partial \sigma^{2}}\left(\frac{D_{z z}}{H^{2}} c\right)-\frac{\partial}{\partial \sigma}\left(W^{\prime} c\right)
$$

where $W^{\prime}$, which represents resuspension through turbulent diffusion, is given by:

$$
W^{\prime}=\frac{\partial}{\partial \sigma}\left(\frac{D_{z z}}{H^{2}}\right)
$$

The vertical diffusion coefficient, $D_{z z}$, is computed as (van Rijn, 1984):

$$
\begin{array}{cc}
D_{z z}=D_{z z}^{\max } & \text { se } z / H>0.5 \\
D_{z z}=-4 D_{z z}^{\max } \sigma(\sigma+1) & \text { se } z / H \leq 0.5
\end{array}
$$

The maximum diffusion coefficient $D_{z z}^{\max }$ is given by:

$$
D_{z z}^{\max }=0.25 \kappa u_{*} H
$$

where $\kappa$ is the van Karman constant $(=0.4), u *$ is the stress velocity:

$$
u_{*}=\sqrt{c_{D}}|U|
$$

and $c_{D}$ is the dimensionless friction coefficient.

\subsubsection{Numerical solution}

Equation (1) is split into three simpler equations which are solved sequentially using different methods:

$$
\begin{gathered}
\frac{\partial c}{\partial t}+u \frac{\partial c}{\partial x}+v \frac{\partial c}{\partial y}=0 \\
\frac{\partial c}{\partial t}=\frac{D_{h}}{H} \frac{\partial}{\partial x_{i}}\left(H \frac{\partial c}{\partial x_{i}}\right) \\
\frac{\partial c}{\partial t}+\frac{\partial\left(\left(w_{s} / H^{\prime}+W^{\prime}\right) c\right)}{\partial \sigma}=\frac{\partial^{2}}{\partial \sigma^{2}}\left(\frac{D_{z z}}{H^{2}}\right)
\end{gathered}
$$

All equations are solved on an unstructured triangular finite element mesh. Equation (11) is solved through an embedded adaptive $4^{\text {th }}$-order Runge-Kutta method (Press et al., 1992). This method allows for a user-specified accuracy (Oliveira and Baptista, 1997, 1998). VELApart also compensates the inaccuracies of the driving flow model at closed boundaries by using only the tangential velocity. Equations (12) and (13) are solved using a random walk method (Dimou, 1992, Moeller, 1993).

\section{Summary of model set-up and application}

The circulation model domain extends from the river at the wastewater facility discharge location, upstream of the tidal intrusion limit, to $4.5 \mathrm{~km}$ away from the inlet (Figure 3). Simulations were performed for two distinct periods for which bathymetric field data were measured (May and September 2008, Table 1, Figure 4) selected to highlight the effect of waves and inlet morphology. The bathymetries were measured in May and 
September in the lower estuary, beach and nearshore. The September bathymetry presents a more meanderized channel than the bathymetry of May, but the latter has a significant constriction between zones 3 and 4 (Figures 4 and 7). Elsewhere, the bathymetry was assumed unchanged and surveys from May 2008 were used. The model was forced by tides, taken from the regional model of Fortunato et al. (2002) for May 2008, river flows measured at the upstream boundary of the model on May $6\left(0.3 \mathrm{~m}^{3} / \mathrm{s}\right)$, and radiation stresses computed from SWAN results. Wind was neglected as wind speed was about $5 \mathrm{~m} / \mathrm{s}$ on both May 6 and September 11. The circulation and transport grid has 40,000 nodes and a resolution between 0.5 and $350 \mathrm{~m}$. This fine resolution is required because the channel is only a few meters wide at low tide. The hydrodynamic time step was set to $5 \mathrm{~s}$ and a warm-up period of 2 days was used. The Manning friction coefficient was set to $0.015 \mathrm{~m}^{1 / 3} / \mathrm{s}$, after a preliminary calibration. Selected model / data comparisons show that both tidal (Figure 5) and wave (Figure 6) propagation are realistically reproduced, although further improvements are still under way (e.g., a more accurate mean sea level at the ocean boundary, a more detailed bathymetry in the tidal flats, a calibration of the wave breaking coefficient).

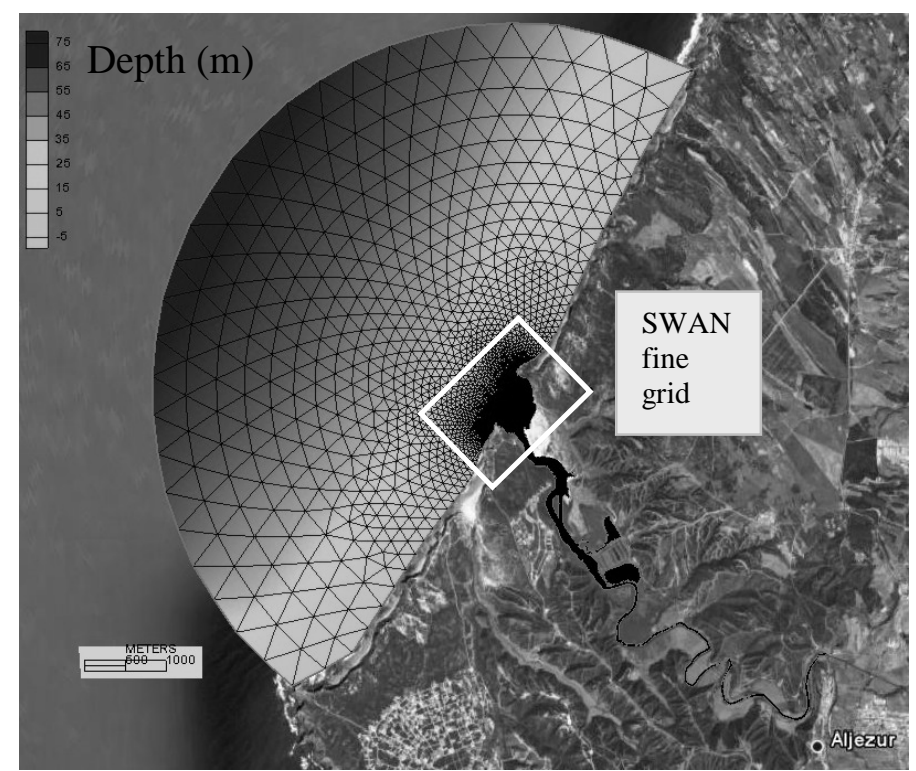

Figure 3. Computational grid for the circulation and transport model. The rectangle represents the boundaries of the finer wave model grid.

SWAN was run in stationary mode, and was updated every 20 minutes. SWAN was forced by the wave spectra computed with a validated application of WW3 to the North Atlantic (Dodet et al., 2010) in simulations $\mathrm{H} 2$ and $\mathrm{H} 4$, and by constant wave conditions in simulation $\mathrm{H} 5$ and $\mathrm{H} 6$ (significant wave height: $3 \mathrm{~m}$; peak period: $13 \mathrm{~s}$; direction: NW). Two Cartesian nested grids are used: the coarser grid has a uniform resolution of 
$200 \mathrm{~m}$, oriented North, and the fine grid (Figure 3) is curvilinear, with a resolution ranging from $20 \mathrm{~m}$ to $6 \mathrm{~m}$ in the surf zone and $3 \mathrm{~m}$ at the inlet.
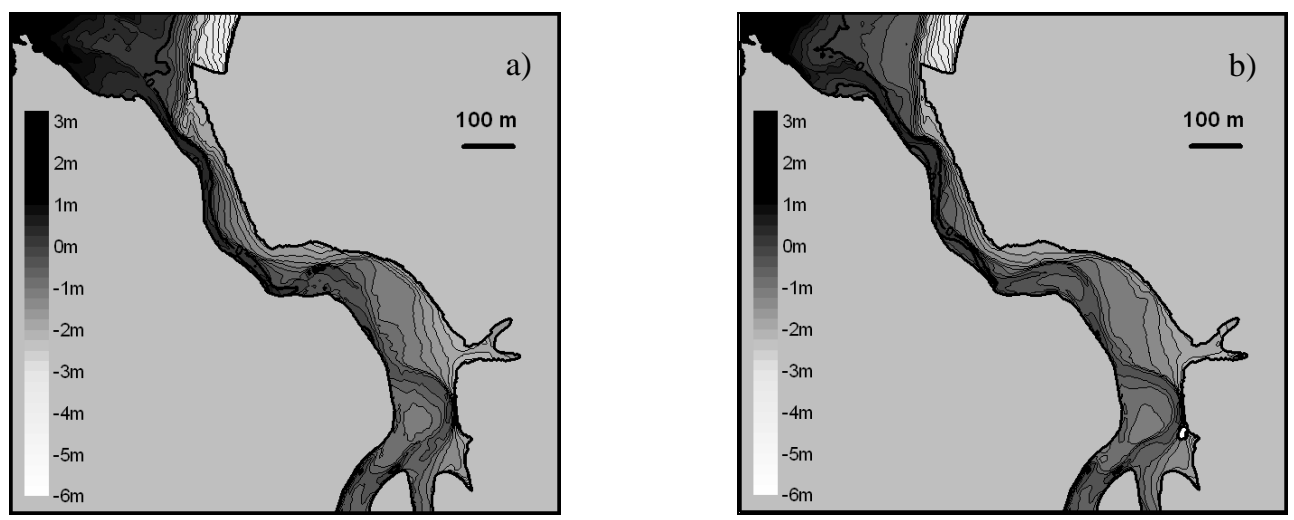

Figure 4. a) May 2008 bathymetry. b) September 2008 bathymetry

Table 1. Hydrodynamic model simulations

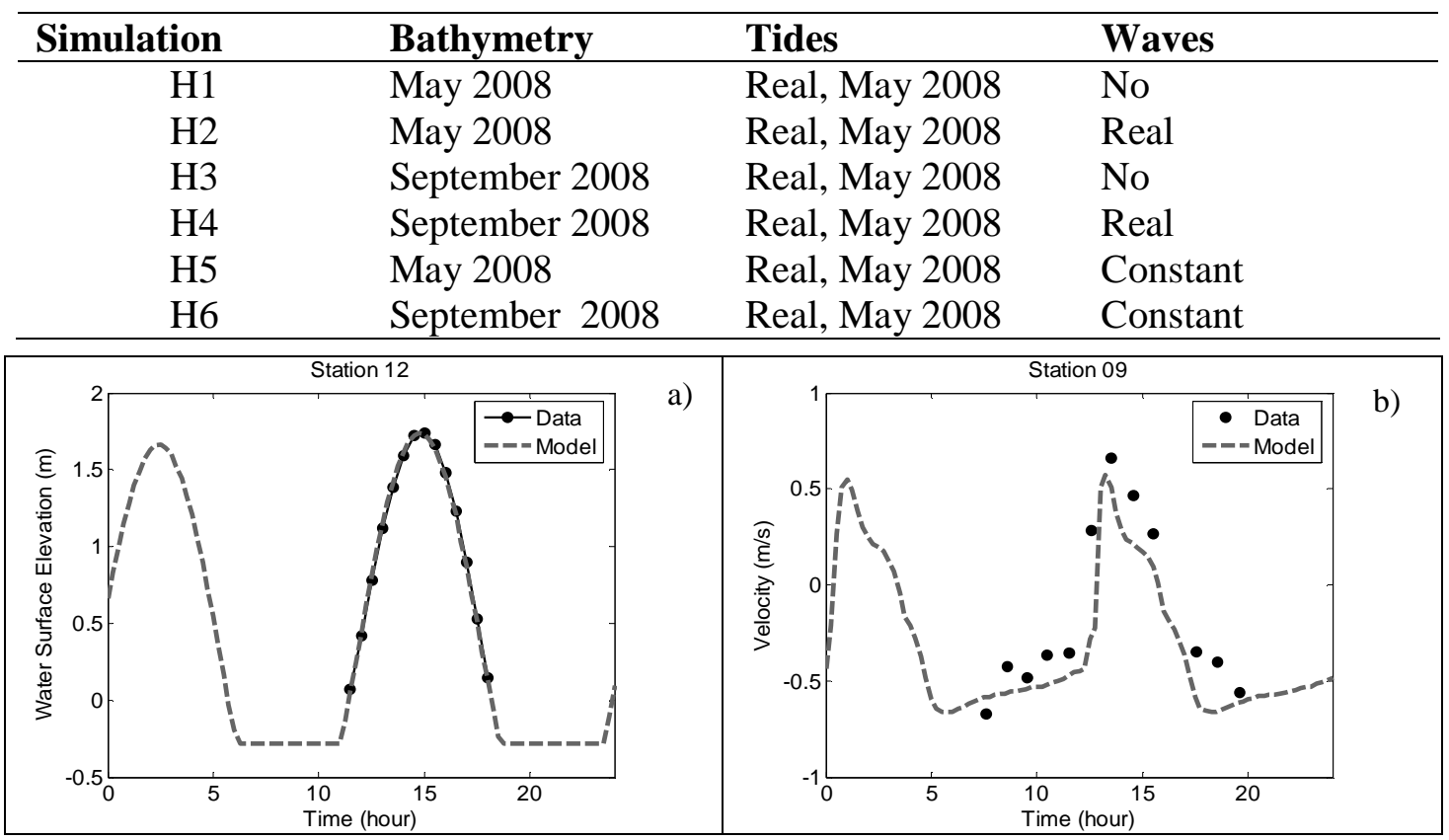

Figure 5. Model / data comparisons for simulation H2 (May 2008): a) water levels in the surf zone; $b$ ) velocities at the inlet (positive values indicate flood). Stations locations are shown in Figure 7.

Two types of transport simulations were performed.

1. The sediment pathways were qualitatively estimated using VELApart in quasi-3D mode. Sediment diameter was set to $0.35 \mathrm{~mm}$, a representative value for $\mathrm{d}_{50}$ in the lower estuary. Sediments were released in the middle of the water column, in the 
lower estuary (where bottom sediments are sandy) and followed until they reached the bottom. Sediment motion was simulated from May 1 to 10, 2008 with bathymetry from May (hydrodynamic simulations H1, H2 and H5) and September (H3 and H4).

2. The pathways of pollutants originating at different locations were determined by releasing sets of a few hundred particles around selected areas: the outlet from the aquaculture facility (around kilometer 2.4); near the cattle grazing field (around kilometer 4.5); and the outlet from a sewage water treatment plan (around kilometer 9). The position of these particles was followed in time and mapped on the line that follows the main channel. The central position and standard deviation of the set of particles were then computed at each time step. This evaluation was carried out until $20 \%$ of the particles had left the estuary. These particle model runs were also forced by hydrodynamic simulations H1-H6.

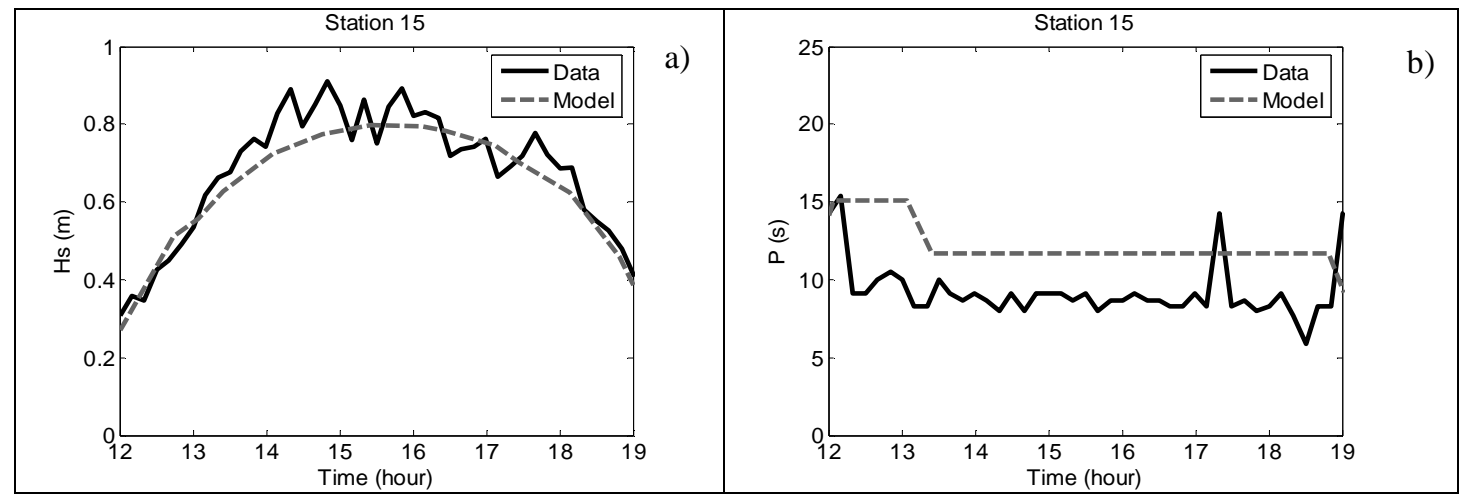

Figure 6. Model / data comparisons for May 6 (simulation H2): a) significant wave height; b) wave period. Stations locations are shown in Figure 7.

\section{Results and discussion}

\subsection{Impact of waves and morphology on sediment dynamics}

Inlet dynamics is mostly driven by waves and tidal currents. Waves affect tidal inlets primarily through the generation of littoral currents, which transport sediments from the surf zone to the inlets, promoting their accretion and feeding flood sand banks. A more subtle effect of waves is associated with the generation of a setup near the coast. In very shallow inlets, this setup can significantly modify the water depth, which in turn affects tidal propagation and distortion into the inlet. Bertin et al. (2009c) showed through numerical experimentation that wave setup reduces ebb-dominance in the Óbidos tidal inlet, which, together with the direct wave-induced transport towards the inlet, should enhance accretion in the lagoon.

In this section, VELApart results are used to confirm these findings and assess how this process affects sediment dynamics. Sediments released in the lower estuary are followed for 10 days in simulations forced by tides alone $(\mathrm{H} 1, \mathrm{H} 3)$, tides and real waves 
(H2, H4) and tides and high waves (H5, H6). Each particle was released at mid-depth, at low tide, high tide, mid-ebb and mid-flood, and followed until it settled on the bottom for the first time. At the end of the simulations, the percentages of sediment particles that settled in 5 different zones (Figure 7) were compared to assess the effect of waves on the flushing of sediments from the estuary.

The phase of the tide when sediment particles are released has a major influence on the results (Figure 8). In order to understand the average behavior of the sediments, results for all the release times were therefore bundled together in the analysis (Figure 9). Results show that as the wave height increases, the percentage of sediments that escape the estuary (zone 1) steadily grows at the expense of those that remain in the lower estuary (zone 4) and on the beach (zone 2). This behavior can be mostly attributed to the wave-generated littoral currents, which drive away the sediments that leave the estuary on ebb, preventing their later reentrance in the estuary. This effect of waves is small in this application, but should be stronger on longer beaches, with larger littoral currents.

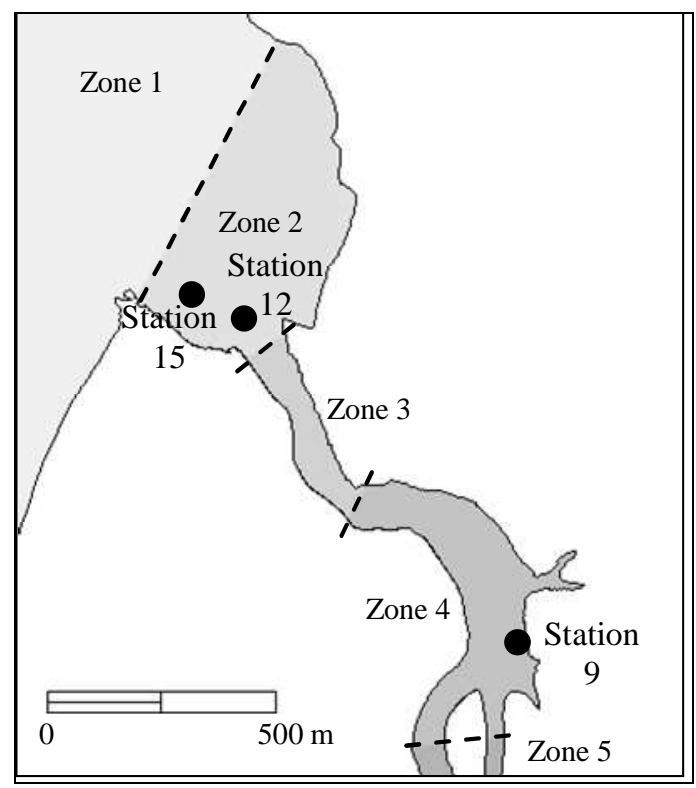

Figure 7. Zones used for the sediment dynamics analysis: 1 - nearshore; 2 - beach; 3/4 - lower estuary; 5 - upper estuary.

A less pronounced effect of waves is the growing percentage of sediments that settle in the upper estuary (zone 5) as the wave height increases. This behavior is consistent with the reduction of ebb dominance associated with the wave setup, and confirms the previous analysis of Bertin et al. (2009c).

In order to assess possible causes for this behavior, three possibilities were considered. Traditionally, tidal asymmetry is analyzed using elevation time series (e.g., Friedrichs and Aubrey, 1988, Fortunato and Oliveira, 2005). Like in many other 
systems, ebbs in the Aljezur estuary are longer than floods. This phenomenon contributes to flood dominance, i.e. higher velocities on flood than on ebb. Considering this behavior alone, wave setup should reduce the non-linear generation of tidal harmonics, thereby reducing flood dominance. Indeed, tidal distortion decreases with the ratio between tidal amplitude in the ocean and the channel depth (Friedrichs and Aubrey, 1988). However, this process should reduce the intrusion of sediments further upstream, contradicting the behavior indicated by the particle model. An alternative explanation must therefore be sought.

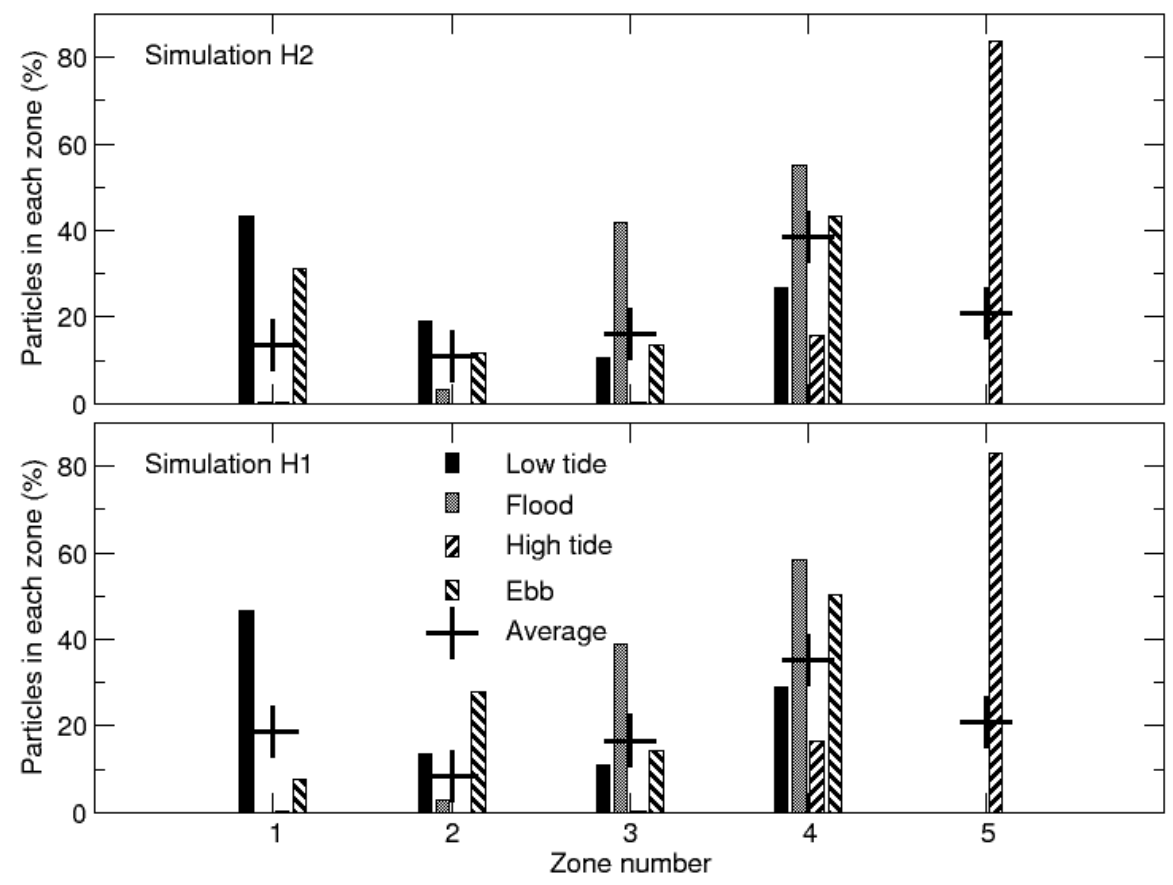

Figure 8. Dependence of the sedimentation patterns on the release time.

Ebbs normally occur at lower tidal elevations than floods. This behavior is illustrated on Figure 10: when the water level is much higher in the sea than in the inlet (flood), it is above mean water level, while the opposite occurs on ebb. In deep estuaries, the difference between the total depth at high and low tide is small, and should not affect velocities significantly. However, in a shallow estuary, the smaller water depths that occur on ebb can have a significant effect on tidal currents, enhancing ebb relative to flood currents. The observed and modeled velocities at the inlet (Figure 5b) confirm this qualitative explanation and show that this effect is significant: although flood is much shorter than ebb, the maximum velocities are similar on ebb and on flood. Hence, residual sediment fluxes at the inlet should be directed downstream. Clearly, ebb-flood duration differences alone do not fully explain the asymmetry in tidal currents in shallow estuaries. 


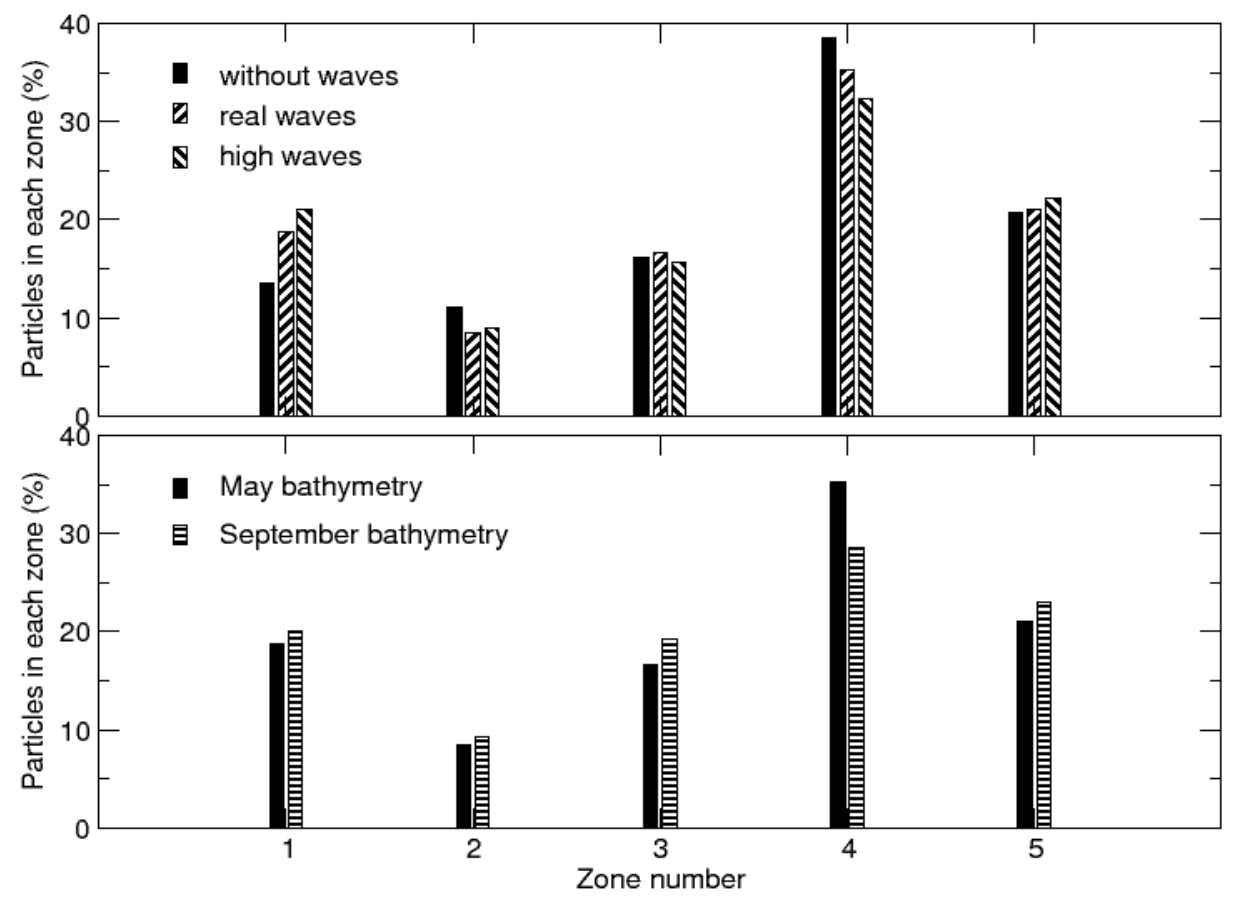

Figure 9. Impact of the hydrodynamics and bathymetry on the sedimentation patterns.

In this context, a small increase in the surface elevation induced by wave setup will have a distinct effect on ebb and flood currents. When velocities are close to the maximum in the estuary, the shallow water equations reduce essentially to a balance between friction and the surface water gradient:

$$
g \nabla \eta \approx-\frac{\tau}{H \rho}
$$

where $g$ is gravity, $\eta$ is the surface elevation, $\tau$ is the bottom stress and $\rho$ is density. Neglecting the effect of the wave setup on the barotropic pressure term in the estuary, equation (14) shows that an increase in the total water depth will lead to an increase in the bottom stress, i.e., in the velocity. However, because the relative increase in water depth is larger on ebb than on flood, velocities will also increase more on ebb than on flood, as confirmed by model results (Figure 11a). Again, this different behavior of ebb and flood velocities in shallow estuaries with wave setup should actually reduce sediment intrusion in the estuary, thus does not explain the behavior predicted by the particle model.

A third consequence of wave action on tidal propagation in shallow estuaries is facilitating tidal propagation by increasing the water depth. Furthermore, as the waves break closer to the shore at high tide, the wave setup at the inlet is higher than at low tide. Hence, wave action raises the water level more at high tide than at low tide, thereby increasing tidal amplitude in the estuary (Figure 11b). This increased tidal penetration 
due to waves should promote sediment intrusion upstream, and is therefore the most likely explanation for the behavior predicted by VELApart.

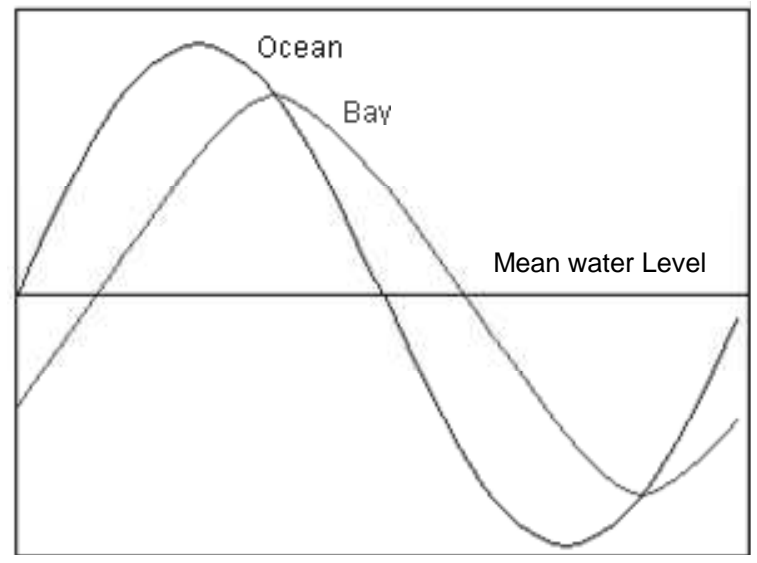

Figure 10. Tidal elevations as a function of time in an embayment, computed with the Keulegan (1967) analytical model (source: www.coastal.udel.edu/faculty/rad/inlet.html) show that ebbs occur at lower water levels than floods. Inlet width: $50 \mathrm{~m}$; inlet length: $8 \mathrm{~km}$; bay planform area: $0.4 \mathrm{~km}^{2}$; ocean tidal amplitude: $1 \mathrm{~m}$; inlet depth: $1 \mathrm{~m}$.

The two phenomena described above - the intensification of the ebb velocities with the wave setup and the larger increase of the water levels at high tide - are related through mass conservation. On flood, velocities remain mostly unchanged by the wave setup, and the tidal prism increases primarily through the enlargement of the water depth; on ebb, the rise of the water levels is modest, and the tidal prism increases through the intensification of the velocities.

A similar comparison was made for simulations without waves using the May (H1) and September (H3) bathymetries. Results show that the differences are small but nonnegligible. With the September bathymetry, there are fewer sediment particles settling in zone 4 than with the May bathymetry (Figure 9). A possible explanation for the observed differences lies in the velocity fields. With the May bathymetry, there is an area upstream of the limit between zones 3 and 4 that has relatively small velocities (Dotted circle in Figure 12). It is therefore likely that sediment coming both from upstream and downstream settle in that area. In contrast, the flow field is smoother with the September bathymetry, avoiding a preferential area for deposition.

\subsection{Impact of waves and morphology on the pathways of pollutants in the Aljezur stream}

The impact of bathymetry and wave-induced hydrodynamics (littoral currents and wave set-up) on suspended pollutants is investigated here for the same conditions used for the sediment analysis, based on three sets of particles released near the potential sources of contamination in the Aljezur coastal stream (Figure 13a). 
Results show that, like for sediments, pollutant pathways strongly depend on the release time within the tidal cycle, in particular for the Aquaculture set (Figure 13b-d). However, the upstream intrusion limit of the plumes seems to be almost independent of this factor. The current strategy for the water renewal of aquaculture ponds during ebb, which appears adequate to minimize contamination and promote flushing, may increase the area subject to contamination as the downstream limit is further away. On the other hand, the larger plume contributes towards its dilution and reduces the presence of concentrations above the regulation limits.

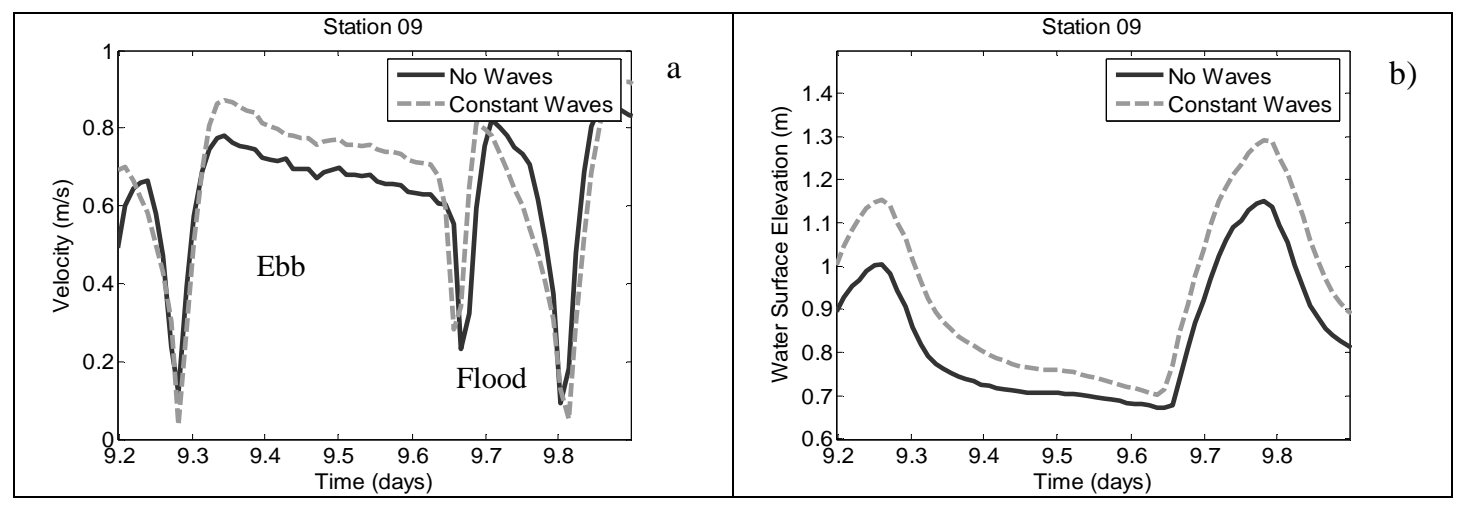

Figure 11. Effect of waves on circulation at the limit between the upper and lower estuary for simulations $\mathrm{HI}$ and H5: a) velocity; b) elevation.

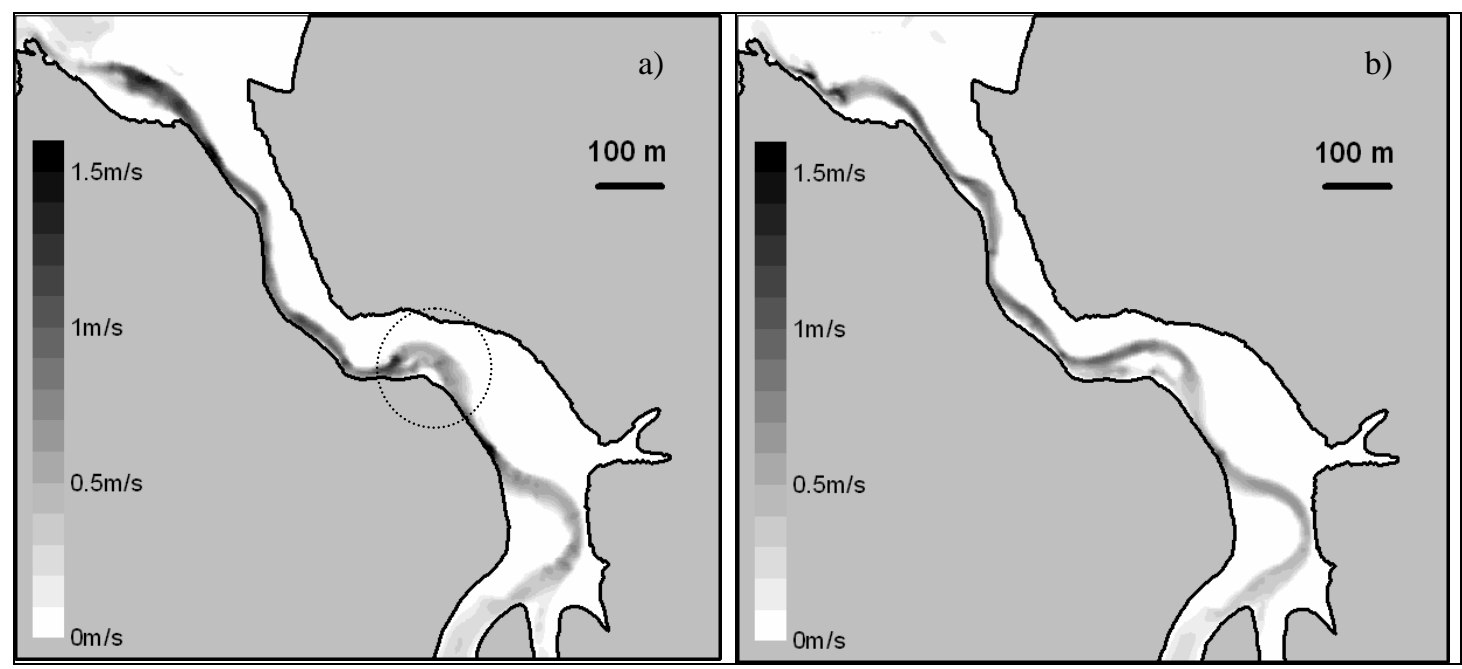

Figure 12. Velocities $(\mathrm{m} / \mathrm{s})$ at maximum ebb for runs: a) $\mathrm{Hl}$; b) $\mathrm{H3}$. 


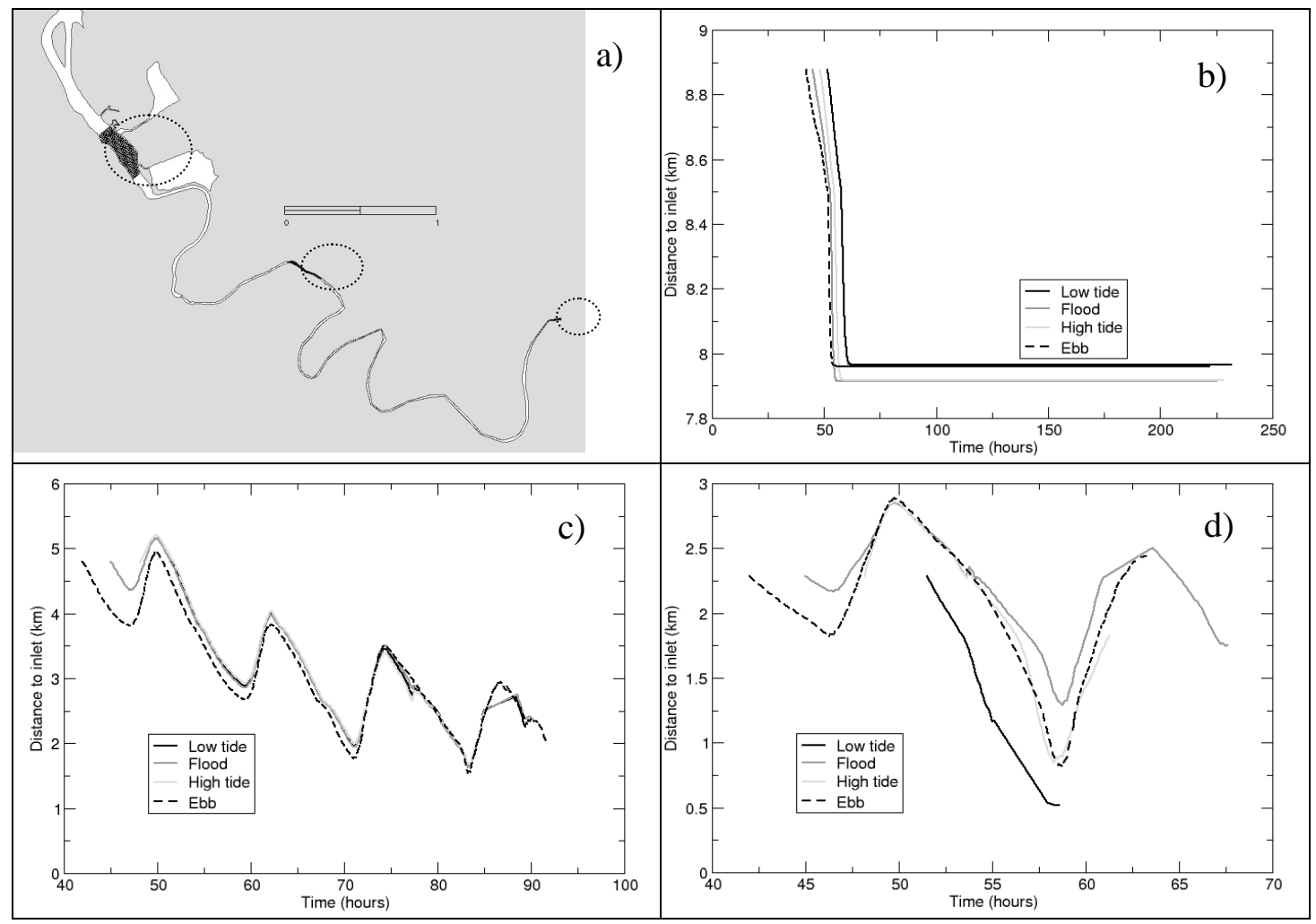

Figure 13.a) Location of sets release (dotted lines); evolution in space and time of the b) Wastewater set; c) Pasture set; d) Aquaculture set.

The impact of waves on the pollutants pathways is very significant for the larger waves simulated, which, as for sediments, considerably promote the penetration of pollution upstream (Figure 14b). In contrast, the effect of the smaller waves on the pathways of pollutants is negligible, in particular for the sets released upstream (Figure 14c). These results indicate that residence times in this system will be significantly affected by large waves: on the one hand, waves increase the tidal prism, thereby reducing residence times (Figure 14a); on the other hand, by promoting tidal penetration, waves can foster the movement of pollutants towards upstream (Figure 14b).

The bathymetry of the lower estuary has a significant impact on pollutant pathways but less important than large waves (Figure 14c). The bathymetry at the end of maritime summer (September) leads to a faster export of pollutants to the coast, as the inlet should be less constrained due to a reduction in wave action (Figure 14d). The analysis of the September hydrodynamics shows that tide propagates further upstream as compared to May, transporting pollutants accordingly. This conclusion needs to be further validated and correlated with tidal prism through simulations with other bathymetric data sets, measured on a monthly basis from March to September 2009. 


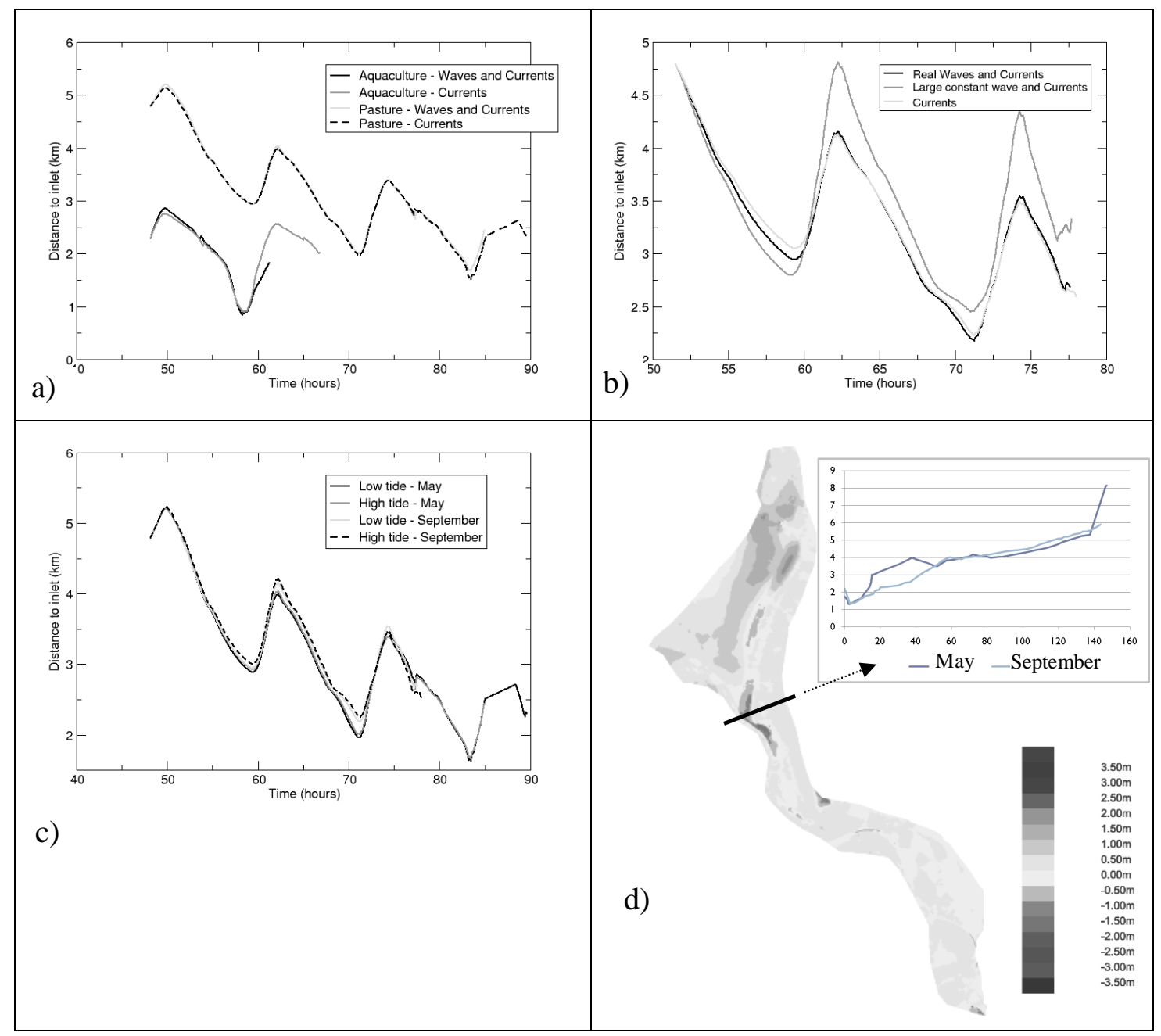

Figure 14.a) Evolution in space and time of a) Aquaculture and Pasture sets for real waves and currents (H2) and currents only (H1), for high tide; b) the Pasture set for the high tide release and for real and large waves and currents (H2, H5) and currents only (H1); and c) the Pasture set for the low and high tide releases for both bathymetries (H1, H3). d) Bathymetric changes between September and May, 2008.

\section{Summary and conclusions}

The behavior of estuaries associated with small coastal streams exhibits some qualitative differences relative to large estuaries. In particular, the impact of the wave setup on the total depth can be significant due to the small depths of their inlets, leading to a major effect of waves on tidal propagation and distortion. Simultaneously, because the ebb jets are weak, the importance of the littoral currents on the fate of the water masses leaving the estuary is stronger than in large estuaries. This paper presented a preliminary 
analysis on the effect of wave-induced processes on the exchange of dissolved and particulate material between small estuaries and the sea.

Numerical experiments showed that the setup due to waves can promote sediment and pollutant transport towards the head of the estuary. Several phenomena were analyzed to determine a possible cause for this behavior. Two of them should actually have the opposite effect. On the one hand, wave setup reduces the tidal amplitude to depth ratio and the ratio between flood and ebb currents. These reductions should promote the flushing of sediments from the estuary. However, the larger depths in the estuary caused by the wave setup also promote tidal intrusion and increase the tidal range, which should enhance the transport of sediment and dissolved material upstream. The growth of the tidal range is attributed to the variation of the wave setup during the tidal cycle. During flood, at high tide, the waves break closer to the beach than at low tide. The resulting wave setup near the inlet is therefore higher at high tide, significantly raising the water level inside the estuary. At low tide, the water level is also raised by the wave setup, but less. As a result, the tidal range increases.

Because there are simultaneous processes at play with opposite consequences, the generalization of these conclusions is risky. Indeed, the dominant physical processes that determine whether waves will promote or hinder sediment flushing from a shallow estuary may depend on the particular system, or even on its particular conditions.

Future research will address questions raised by the present analysis. We will:

- Improve wave-current interactions by including current and spatially-varying water level effects on wave simulations;

- Improve the integrated analysis of water renewal through residence times calculations, following the Oliveira and Baptista (1997) methodology, and compare it with fecal bacteria decay times, obtained from laboratory experiments for Aljezur;

- Dynamically account for bathymetric changes, by including VELApart in MORSYS2D and evaluating pollutant pathways forced by hydrodynamics computed for a dynamically updated bathymetry;

- Extend the water quality analysis to account for fecal contamination processes and allow for a comparison of the relative impact of physical and water quality processes and the different sources of contamination in the system. This analysis includes a 3D coupled analysis of fecal contamination and morphodynamics, which was already started in Rodrigues et al. (2009b), through the application of the 3D coupled hydrodynamic-ecological ECO-SELFE model of Rodrigues et al. (2009a).

\section{Acknowledgements}

This work was partially sponsored by FEDER and the Fundação para a Ciência e a Tecnologia, projects MADyCOS (PTDC/ECM/66484/2006) and BAYBEACH (PTDC/CTE-GEX/66893/2006). Marta Rodrigues was also funded by FCT grant SFRH/BD/41033/2007. The authors thank the developers of the models ELCIRC and SWAN for making their source codes available. 


\section{References}

Battjes, J.A. and Janssen, J.P.F.M., 1978. "Energy loss and set-up due to breaking of random waves." Proc. 16th Int. Conf. Coastal Engineering, ASCE, 569-587.

Bertin, X., Oliveira, A. and Fortunato, A.B. 2009a. "Simulating morphodynamics with unstructured grids: description and validation of a modeling system for coastal applications." Ocean Modelling, 28(1-3), 75-87.

Bertin, X., Fortunato, A.B. and Oliveira, A., 2009b. "Morphodynamic modeling of the Ancão Inlet, South Portugal." Journal of Coastal Research, SI56, 10-14.

Bertin, X., Fortunato, A.B. and Oliveira, A., 2009c. "A modeling-based analysis of processes driving wave-dominated inlets." Cont. Shelf Research, 29(5-6), 819-834.

Blain, C.A. and M. Cobb, 2003. "Application of a shelf-scale model to wave-induced circulation, Part I: Alongshore currents on plane and barred beaches." NRL/FR/732003-10,046, Naval Research Laboratory, Department of the Navy, 25 pp.

Booij, N., Ris, R.C. and Holthuijsen, L.H., 1999. "A third generation wave model for coastal regions; Part I: model description and validation." Journal of Geophysical Research, 104, 7649-7666.

Dimou, K. 1992. "3-D Hybrid Eulerian-Lagrangian Particle Tracking Model for Simulating Mass Transport in Coastal Water Bodies." Ph.D. Dissertation, Massachusetts Institute of Technology, Cambridge, USA.

Dodet, G., Bertin, X. and Taborda, R. 2010. "Wave climate variability in the North-East Atlantic Ocean over the six last decades." Ocean Modelling, 31 (3-4), 120-131.

Fortunato, A.B. and Oliveira, A. 2004. "A modeling system for tidally driven long-term morphodynamics," Journal of Hydraulic Research, 42(4), 426-434.

Fortunato, A.B. and Oliveira, A. 2005. Influence of intertidal flats on tidal asymmetry, $J$. Coastal Research, 21(5), 1062-1067.

Fortunato A.B., Bertin, X. and Oliveira, A. 2009. "Space and time variability of uncertainty in morphodynamic simulations." Coastal Engineering, 56(8),886-894.

Fortunato, A.B., Pinto, L.L., Oliveira, A. and Ferreira, J.S. 2002. "Tidally-generated shelf waves off the western Iberian coast." Cont. Shelf Research, 22(14), 1935-1950.

Friedrichs, C.T. and Aubrey, D.G. 1988. "Non-linear tidal distortion in shallow wellmixed estuaries: a synthesis." Estuarine, Coastal and Shelf Science, 27, 521-545.

Keulegan, G.H. 1967. "Tidal Flow in Entrances." U.S. Army Corps of Engineers, Committee on Tidal Hydraulics, Tech. Bull. 14, Vicksburg.

Longuet-Higgins, M.S. and Stewart, R.W. 1964. "Radiation stresses in water waves: a physical discussion with applications." Deep-Sea Research, 11, 529-562.

Madsen, O., Poon, Y.-K., and Graber, H. 1988. "Spectral wave attenuation by bottom friction: theory." Proceedings of the 21st International Conference on Coastal Engineering, 492-504.

Moeller, J.C., 1993. "Comparison of Eulerian-Lagrangian, Random Walk, and Hybrid Methods of Modeling Pollution Transport." M.Sc. Thesis, Massachusetts Institute of Technology, Cambridge, USA.

Oliveira, A. and Baptista, A.M. 1997. "Diagnostic modeling of residence time in 
estuaries." Water Resources Research , 33/8, 1935-1946

Oliveira, A. and Baptista, A.M. 1998. "On the role of tracking on Eulerian-Lagragian solutions of the transport equation." Advances in Water Resources, 21(7), 539-554.

Oliveira, A. and Fortunato, A.B. 2002a. "Towards an Oscillation-Free, Mass Conservative, Eulerian-Lagrangian Transport Model." Journal of Computational Physics, 183(1), 142-164.

Oliveira, A. and Fortunato, A.B. 2002b. "VELApart User's Manual (Version 3.1): A Quasi-3D Particle-Tracking Model for Shallow Water Simulations" Rel 82/02 LNEC.

Oliveira, A., Fortunato, A.B. and Baptista, A.M. 2000. "Mass Balance in EulerianLagrangian Transport Simulations in Estuaries." Journal of Hydraulic Engineering, 126(8), 605-614

Oliveira, A., Fortunato, A.B., and Rego, J.R.L. 2006. "Effect of morphological changes on the hydrodynamics and flushing properties of the Óbidos lagoon (Portugal)." Continental Shelf Research, 26/8: 917-942.

Oliveira, A., Fortunato, A.B., Rodrigues, M. and Azevedo, A. 2007. "Integration of physical and water quality models." La Houille Blanche, 4, 40-46.

Oliveira, A., Rodrigues, M., Fortunato, A.B. and Bertin, X. 2008. "Numerical analysis of the impact of morphodynamics on the water quality of a coastal lagoon." Estuarine and Coastal Modeling X, Spaulding [Ed.], ASCE, 651-670.

Press W.H., Teukolsky, S.A., Vetterling, W.T. and Flannery, B.P. 1992. "Numerical recipes in Fortran." Cambridge University Press, New York, 704-716.

Rodrigues, M., Oliveira, A., Queiroga, H., Fortunato, A.B. and Zhang, Y.J. 2009a. "Three-Dimensional Modeling of the Lower Trophic Levels in the Ria de Aveiro (Portugal)." Ecological Modelling, 220, 1274-1290.

Rodrigues, M., Oliveira, A., Queiroga, H., Guerreiro, M., Fortunato, A.B., Cravo, A., Freitas, M.C., Menaia, J., and Dodkins, I. 2009b. "Dynamic modeling of dissolved oxygen in the Aljezur coastal stream." Conference Handbook, ISEM 2009 Conference, Université Laval, Québec City, Canada.

Suzuki, M.S., Ovalle, A.R.C. and Pereira, E.A. 1998. "Effects of sand bar openings on some limnological variables in a hypertrophic coastal lagoon of Brazil." Hydrobiologia, 368, 111-122

Tolman, H.L., Balasubramaniyan, B., Burroughs, L.D., Chalikov, D.V., Chao, Y.Y., Chen, H.S. and Gerald, V.M., 2002. "Development and implementation of wind generated ocean surface wave models at NCEP." Weather Weat. and forecasting, 17, 311-333.

Van Rijn, L.C., 1984. "Sediment Transport - Part 2: Suspended Load Transport." Journal of Hydraulic Engineering, 110(11), 1613-1641.

Zhang, Y.-L., Baptista, A.M. and Myers, E. P. 2004. "A cross-scale model for 3D baroclinic circulation in estuary-plume-shelf systems: I. Formulation and skill assessment." Continental Shelf Research, 24(18), 2187-2214. 